ARTICLE

https://doi.org/10.1038/s41467-019-09215-9

\title{
Unusual substrate and halide versatility of phenolic halogenase PltM
}

Shogo Mori ${ }^{1}$, Allan H. Pang ${ }^{1}$, Nishad Thamban Chandrika', Sylvie Garneau-Tsodikova ${ }^{1}$ \& Oleg V. Tsodikov ${ }^{1}$

Controlled halogenation of chemically versatile substrates is difficult to achieve. Here we describe a unique flavin-dependent halogenase, PltM, which is capable of utilizing a wide range of halides for installation on a diverse array of phenolic compounds, including FDA-approved drugs and natural products, such as terbutaline, fenoterol, resveratrol, and catechin. Crystal structures of PltM in complex with phloroglucinol and FAD in different states yield insight into substrate recognition and the FAD recycling mechanism of this halogenase.

\footnotetext{
${ }^{1}$ Department of Pharmaceutical Sciences, College of Pharmacy, University of Kentucky, Lexington, KY 40536-0596, USA. These authors contributed equally: Shogo Mori, Allan H. Pang. Correspondence and requests for materials should be addressed to S.G-T. (email: sylviegtsodikova@uky.edu) or to O.V.T. (email: oleg.tsodikov@uky.edu)
} 
alogenation is an important chemical modification with a potential to increase biological activity and bioavailability of molecules ${ }^{1,2}$. Moreover, halogen groups can be further synthetically elaborated by transition metalcatalyzed coupling reactions ${ }^{3-5}$. Halogenase enzymes are attractive potential halogenating tools, because, unlike synthetic halogenation, these enzymes ensure both regiospecificity and green chemistry.

Flavin adenine dinucleotide (FAD)-dependent tryptophan (Trp) halogenases have been the focus of development as halogenation tools ${ }^{6}$. Mutagenesis of Trp halogenase RebH increased its stability, catalytic efficiency ${ }^{7}$, and substrate scope, to halogenate natural products and drug-like molecules ${ }^{8}$. Furthermore, halogenation on a gram scale by this enzyme was achieved by cross-linking it to coupled enzymes ${ }^{9}$. A recent study of the detailed substrate profile of several bacterial Trp halogenases (including RebH) and two fungal phenolic halogenases (Rdc2 and Gsfl) indicated that Trp halogenases displayed preference towards indole, phenylpiperidine, phenylpyrrole, and phenoxyaniline derivatives as substrates, while phenolic halogenases had a narrow substrate profile of some anilines, phenol derivatives ${ }^{10}$, and natural products such as macrolactones and curcumin ${ }^{11,12}$. While the substrate profiles of some FAD-dependent Trp halogenases appear to be quite broad ${ }^{10}$, the halide spectrum of characterized Trp and phenolic halogenases has been limited to at most two halides: most commonly chloride $\left(\mathrm{Cl}^{-}\right)$and bromide $\left(\mathrm{Br}^{-}\right)$ions, and for a phenolic halogenase $\mathrm{Bmp} 5$, bromide $\left(\mathrm{Br}^{-}\right)$ and iodide $\left(\mathrm{I}^{-}\right)^{13}$.

In these enzymes, the enzyme-FAD complex catalyzes conversion of a halide ion into a highly reactive hypohalous acid HOX, which diffuses through a protein channel protected from solvent to the substrate binding site, where it is proposed to react with a catalytic lysine residue to form a haloamine adduct $^{14-16}$, or to form hydrogen bonds with catalytic lysine and glutamic acid residues to act as an active oxidant ${ }^{17}$, with subsequent halogenation of the substrate. FAD is usually a prosthetic group that is tightly and, in some cases, covalently bound to the enzyme, co-purifying with it $^{18}$. Some FAD-dependent halogenases use FAD that can dissociate from the enzyme for reduction (Supplementary Table 1) ${ }^{14,19,20}$. How FAD can dissociate and rebind into the confines of its binding site remains unclear.

A bacterial halogenase PltM was originally identified as one of three putative halogenases encoded in the biosynthetic gene cluster of pyoluteorin, an antifungal compound containing a dichloropyrrole moiety ${ }^{21}$. Recently, PltM was elegantly demonstrated to catalyze mono- and dichlorination of phloroglucinol (1) (Fig. 1), yielding, instead of a biosynthetic intermediate, a compound that serves as a potent transcriptional regulator of the pyolyteorin biosynthesis ${ }^{22}$, whereas another halogenase, PltA, which acted on a peptidyl carrier protein loaded pyrrole, was shown to generate dichloropyrrole ${ }^{23,24}$. Herein, we report the wide substrate profile and the unusually large halide versatility of PltM and its crystal structures that reveal a unique recycling mechanism of FAD.

\section{Results}

Halide versatility of PltM. To explore the halide profile of PltM, we first tested halogenation of 1 by PltM with $\mathrm{NaF}, \mathrm{NaCl}, \mathrm{NaBr}$, and $\mathrm{NaI}$ used individually in a reaction mixture. We identified chlorinated, brominated, and iodinated, but not fluorinated $\mathbf{1}$ as products (Fig. 2a, Supplementary Fig. 1, Supplementary Table 2). To our knowledge, PltM is the only example of an FADdependent halogenase that is able to use three different halides, $\mathrm{Cl}^{-}, \mathrm{Br}{ }^{-}$and $\mathrm{I}^{-}$. We observed mono- and dihalogenation of $\mathbf{1}$ with chloride and iodide, but only mono-halogenation with bromide; trihalogenation was never observed. We then carried out competitive halogenation assays of $\mathbf{1}$, where two different halides $\left(\mathrm{Cl}^{-} / \mathrm{Br}^{-}, \mathrm{Cl}^{-} / \mathrm{I}^{-}\right.$, or $\left.\mathrm{Br}^{-} / \mathrm{I}^{-}\right)$were present in the reaction at equimolar ratios (Fig. 2b, Supplementary Figs. 2-4, Supplementary Table 2). Each of these reactions yielded monohalogenated products of either halogen and diiodinated 1 where $\mathrm{NaI}$ was used, whereas products halogenated by two different halides were not observed. In an attempt to obtain a heterodihalogenated product, we used compound $\mathbf{1}$ in the presence of a 10-fold molar excess of $\mathrm{NaCl}$ or $\mathrm{NaBr}$ over $\mathrm{NaI}$ (Fig. 2c, Supplementary Figs. 5, 6, Supplementary Table 2). For the $\mathrm{NaCl} / \mathrm{NaI}$ mixture, we identified all possible mono- and dihalogenated products, including chloro-iodinated $\mathbf{1}$. For $\mathrm{NaBr} / \mathrm{NaI}$, we identified mono-brominated, mono-iodinated, and diiodinated $\mathbf{1}$, and no additional products were observed. In fact, no further halogenation of the mono-brominated species was observed in any reaction.

Substrate profile of PltM. Having established the halide versatility of PltM, we next set out to investigate its substrate profile. We first tested a set of 20 structurally diverse small molecules, most, but not all of which were, like 1, phenolic (phenolic derivatives, anilines, nitrobenzene derivative) and included L-Trp (Fig. 3a, Supplementary Fig. 7). All compounds were tested for chlorination and iodination (Fig. 3b, Supplementary Figs. 8-30, Supplementary Table 3 ). The products were detected and identified by liquid chromatography-mass spectrometry (LC-MS); chlorinated products were identified by the calculated mass and isotope ratio, and iodinated products were identified by the calculated mass, also using the corresponding chlorination reaction as a control. PltM catalyzed halogenation of 18 of the 20 compounds tested, exhibiting remarkable substrate versatility for phenolic compounds (Fig. 3b). The enzyme halogenated all phenolic (1-16) and aniline (16-18) derivatives tested, while it did not halogenate the nitrobenzene derivative 19. These data suggest that the phenyl compounds with electron donating groups can be accepted by PltM as substrates even when one hydroxyl group is substituted with a moderate electron withdrawing group, such as aldehyde (12), ketone (13), and carboxylic acid (14). On the other hand, the strongly electron withdrawing nitro group is not tolerated. This correlation of the substrate electron withdrawing character with halogenation activity is consistent with other phenolic halogenases ${ }^{10}$. The halogenated L-Trp (20) was not observed, indicating that PltM is not a Trp

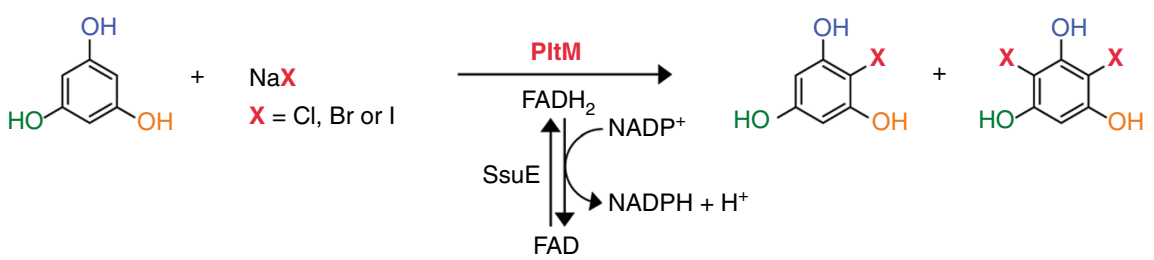

Fig. 1 Halogenation by PltM. Schematic representation of phloroglucinol (1) halogenation by PltM 
a

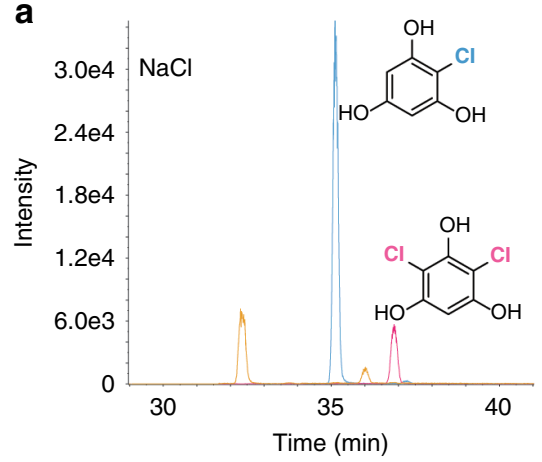

b

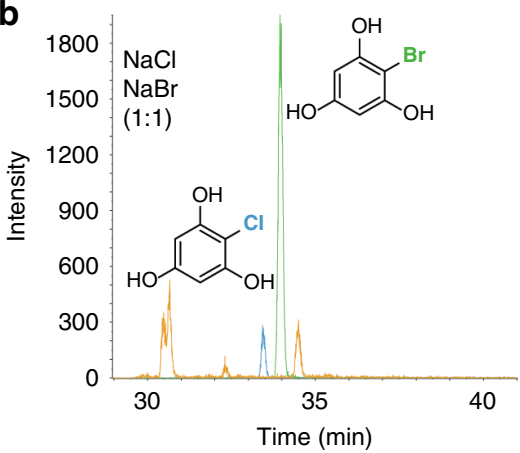

C

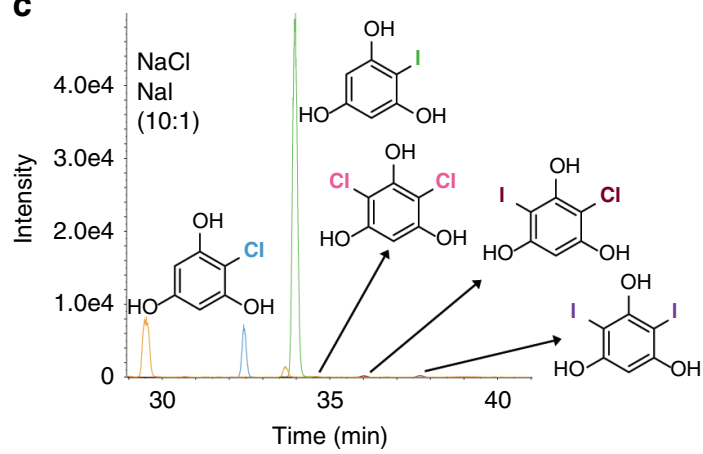

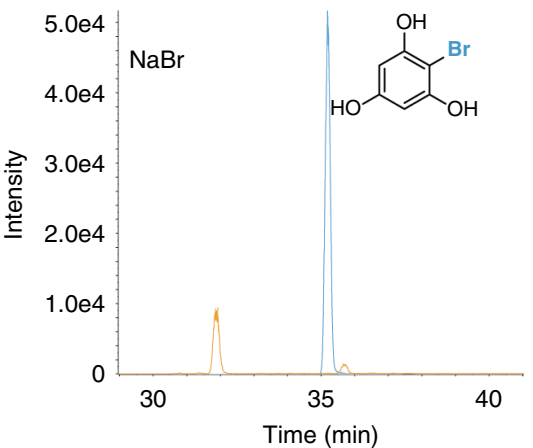
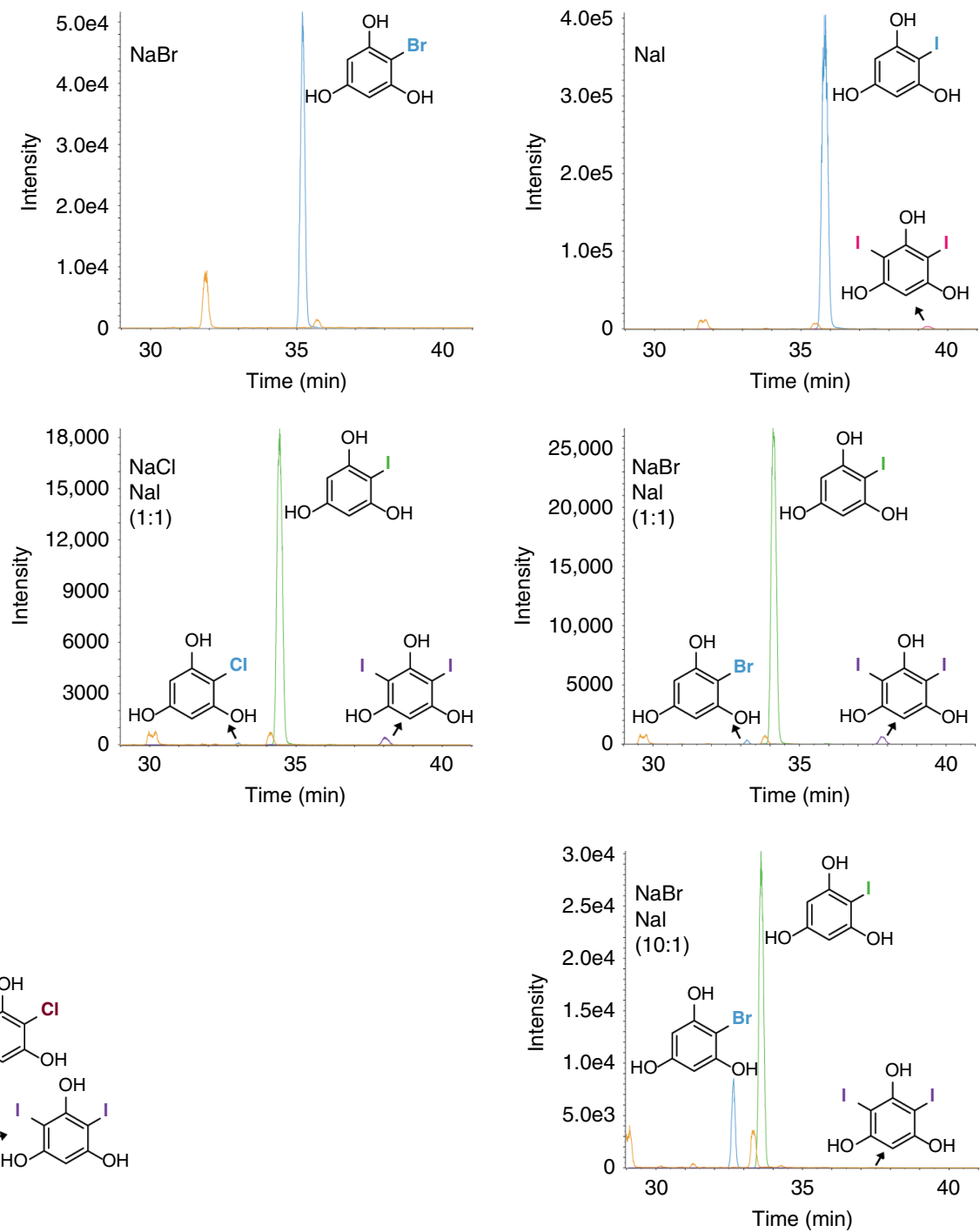

Fig. 2 Halogenation of phloroglucinol (1) by PItM. a XIC traces showing the homo-halogenation of $\mathbf{1}$ by PltM with $\mathrm{NaCl}$ (left), $\mathrm{NaBr}$ (middle), and Nal (right) as halide sources. Blue and pink traces depict mono-halogenation and dihalogenation, respectively. $\mathbf{b}$ Halogenation of $\mathbf{1}$ by PItM with equimolar ratio of $\mathrm{NaCl} / \mathrm{NaBr}$ (left), $\mathrm{NaCl} / \mathrm{Nal}$ (middle), and $\mathrm{NaBr} / \mathrm{Nal}$ (right). Blue and green traces show mono-halogenation with smaller and larger halogens, respectively; while purple trace indicates dehalogenation. c Halogenation of 1 by PltM with $\mathrm{NaCl} / \mathrm{Nal}$ (left) and $\mathrm{NaBr} / \mathrm{Nal}$ (right) in a 10:1 ratio. Blue and green traces show mono-halogenation with smaller and larger halogens, respectively; while purple and pink traces indicate homo-dihalogenation with smaller and larger halogens, respectively. The brown trace displays hetero-dihalogenated products. The orange trace shows the unreacted substrate $\mathbf{1}$<smiles>[R6]c1cc([R])c([R6])c([R])c1</smiles>

1: $\mathrm{R}_{1}=\mathrm{R}_{3}=\mathrm{R}_{4}=\mathrm{OH} ; \mathrm{R}_{2}=\mathrm{H}$ 2: $R_{1}=O H ; R_{2}=R_{3}=R_{4}=H$ 3: $R_{1}=R_{3}=O H ; R_{2}=R_{4}=H$ 4: $R_{1}=R_{2}=R_{3}=O H ; R_{4}=H$ 5: $R_{1}=R_{2}=R_{4}=O H ; R_{3}=H$ 6: $R_{1}=O H ; R_{2}=R_{4}=H ; R_{3}=O M e$ 7: $\mathrm{R}_{1}=\mathrm{OH} ; \mathrm{R}_{2}=\mathrm{H} ; \mathrm{R}_{3}=\mathrm{R}_{4}=\mathrm{OMe}$ 8: $R_{1}=R_{3}=O H ; R_{2}=C l ; R_{4}=H$

\begin{abstract}
9: $\mathbf{R}_{1}=\mathrm{R}_{3}=\mathrm{OH} ; \mathrm{R}_{2}=\mathrm{H} ; \mathbf{R}_{4}=\mathrm{Me}$
10: $R_{1}=R_{3}=O H ; R_{2}=H ; R_{4}=C_{2}$ COOM

11: $R_{1}=R_{3}=O H ; R_{2}=H ; R_{4}=\mathrm{CH}_{2} O H$

12: $\mathbf{R}_{1}=\mathrm{R}_{3}=\mathrm{OH} ; \mathrm{R}_{2}=\mathrm{H} ; \mathbf{R}_{4}=\mathrm{CHO}$

13: $R_{1}=R_{3}=O H ; R_{2}=H ; R_{4}=C O M e$

14: $R_{1}=R_{3}=O H ; R_{2}=H ; R_{4}=\mathrm{COOH}$

15: $\mathrm{R}_{1}=\mathrm{R}_{3}=\mathrm{R}_{4}=\mathrm{OH} ; \mathrm{R}_{2}=\mathrm{COMe}$

16: $R_{1}=O H ; R_{2}=R_{4}=H ; R_{3}=N_{2}$
\end{abstract}

17: $\mathrm{R}_{1}=\mathrm{NH}_{2} ; \mathrm{R}_{2}=\mathrm{H} ; \mathrm{R}_{3}=\mathrm{R}_{4}=\mathrm{OMe}$

18: $R_{1}=R_{3}=N_{2} ; R_{2}=R_{4}=H$

19: $R_{1}=R_{2}=N_{2} ; R_{3}=H ; R_{4}=C O O H$

20: L-Tryptophan

21: Terbutaline

22: Fenoterol

23: Resveratro

24: Catechin

\begin{tabular}{|c|c|c|c|c|c|c|c|c|c|c|c|c|c|c|c|c|c|c|c|c|c|c|c|c|}
\hline & 1 & 2 & 3 & 4 & 5 & 6 & 7 & 8 & 9 & 10 & 11 & 12 & 13 & 14 & 15 & 16 & 17 & 18 & 19 & 20 & 21 & 22 & 23 & 24 \\
\hline Cl & & & & & & & & & & & & & & & & & & & & & & & & \\
\hline diCl & & & & & & & & & & & & & & & & & & & & & & & & \\
\hline I & & & & & & & & & & & & & & & & & & & & & & & & \\
\hline dil & & & & & & & & & & & & & & & & & & & & & & & & \\
\hline $\mathrm{Br}$ & & & & & & & & & & & & & & & & & & & & & & & & \\
\hline
\end{tabular}

Fig. 3 Substrate profile of PItM by LC-MS. a Compounds tested as potential substrates of PItM. b Summary of halogenation assay results. The top row and left column indicate the tested substrate and expected halogenation, respectively. Observed and unobserved halogenation are indicated by blue and gray boxes, respectively, while white boxes indicate untested halogenation 
a

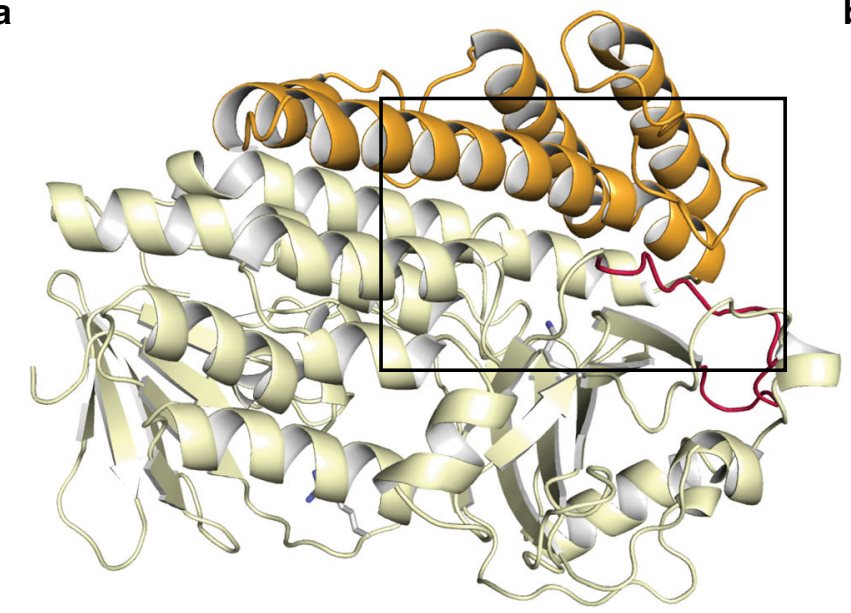

C

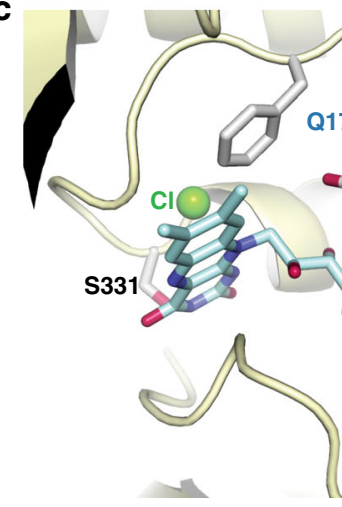

b

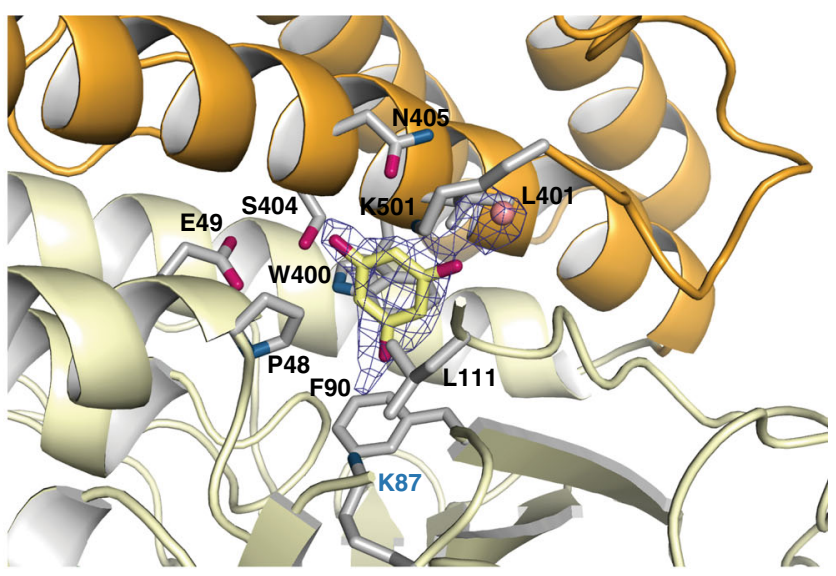

Fig. 4 Crystal structures of PItM. a Full view of the structure of PItM with the conserved halogenase fold in pale yellow and the unique C-terminal region in orange. The red loop indicates the $\mathrm{N}$-terminal unconserved region after the 3rd $\beta$-sheet. The substrate binding region is shown by a box. $\mathbf{b} \mathrm{A}$ zoomed in view of the substrate binding site of the structure of PltM-compound $\mathbf{1}$ complex (yellow sticks). Residues lining the substrate binding pocket are shown as gray sticks and the $m F_{\mathrm{o}}-D F_{\mathrm{c}}$ polder omit map contoured at $5.5 \sigma$ is shown by the gray mesh. $\mathbf{c}$ The FAD bound in the holoenzyme state of PltM. $\mathbf{d}$ The FAD bound in a putative FAD binding intermediate state. FAD is represented as turquoise sticks in panels $\mathbf{c}$ and $\mathbf{d}$. The flexible loop that changes conformation upon FAD binding is shown in brown. Key FAD interacting residues are shown as sticks. Bound $\mathrm{Cl}^{-}$and water are shown as green and salmon spheres, respectively

halogenase, and that it is indeed a bona fide phenolic halogenase. As besides 1 the reaction with compound 11 showed very clear signals of chlorinated and iodinated 11, we also tested compound 11 for bromination and fluorination (Supplementary Fig. 19, Supplementary Table 3). We observed mono-bromination of $\mathbf{1 1}$, but not dibromination or fluorination, which is consistent with the halogenation profile on the natural substrate 1. Encouraged by the wide substrate versatility of PltM as established with compounds 1-20, we tested its halogenase activity on four larger molecules containing a phenolic derivative group. We tested the FDA-approved drugs terbutaline (21) and fenoterol (22), both short-acting $\beta_{2}$ adrenoreceptor agonists that contain a resorcinol moiety in their structure (Supplementary Fig. 7). Iodinated terbutaline (both mono and di) and mono-iodinated fenoterol were obtained (Fig. 3b). We also tested the dietary natural products resveratrol (23) and catechin (24), which were both monochlorinated and mono-iodinated by PltM. These results demonstrate that PltM can be utilized for halogenation of larger druglike molecules and natural products.

Crystal structure of PltM and its complex with phloroglucinol. In addition to its remarkable halide versatility and a very broad substrate profile for a phenolic halogenase, PltM is at most $\sim 15 \%$ identical in sequence to other structurally characterized FADdependent halogenases, and it contains a unique C-terminal region (residues 390-502) (Supplementary Fig. 31). These intriguing properties prompted us to obtain a $1.80 \AA$-resolution crystal structure of this enzyme (Supplementary Fig. 32, Supplementary Table 4). The crystal structure of PltM was obtained by the single anomalous dispersion (SAD) method by using ethylmercury derivatized crystals. PltM is a monomer in solution (Supplementary Fig. 32); the crystals of PltM contain four nearly structurally identical monomers per asymmetric unit. A monomer of PltM (Fig. 4a) consists of a large FAD binding fold that is conserved in FAD-dependent halogenases (residues 1-389). FAD and halide were not found in the FAD binding site, consistent with the lack of color of the protein and its crystals (Supplementary Fig. 32). The C-terminal quarter of the protein is a unique helical region not found in other halogenases (Supplementary Fig. 33). The putative substrate binding cleft located in the interface of the FAD binding fold and the C-terminal region leads to a conserved catalytic lysine residue (Lys87), based on structural superimposition of PltM with structures of Trp halogenases bound to L-Trp (Supplementary Fig. 33). Indeed, mutating Lys87 to an alanine yielded a catalytically inactive protein (Supplementary Fig. 34). The C-terminal region then likely helps define the substrate specificity. Soaking crystals of PltM with compound $\mathbf{1}$ yielded a strong and featureful polder omit $m F_{o}-D F_{c}$ electron density ${ }^{25}$ in three out of four substrate binding sites in the asymmetric unit, corresponding to a molecule of compound $\mathbf{1}$ and a water molecule that bridged it with the protein (Fig. 4b). The binding site of compound $\mathbf{1}$ is analogous to 
that of $\mathrm{L}_{\text {-Trp in }}$ the crystal structure of $\mathrm{RebH}^{14}$ and $\operatorname{PrnA}^{16}$ (Supplementary Fig. 33). The nearest carbon atom of compound 1 that can be halogenated is $\sim 4.5 \AA$ away from the Ne of Lys87, further supporting the model. At its entrance, the substrate binding cavity is lined by charged and polar side chains (Glu115, Glu49, Lys501, and Asn405) (Fig. 4b), which would interact favorably with hydroxyl and amino groups on PltM substrates indicated by the activity profile (Fig. $3 \mathrm{~b}$ ). One face of the phenyl ring of 1 is in nonpolar contacts with and Pro48 and Leu111 and the other face stacks approximately orthogonally Trp400 and interacts with Leu401. The phenyl ring of compound $\mathbf{1}$ is stacked nearly orthogonally against Phe90. This residue likely helps orient the substrate for halogenation. The hydroxyl groups of bound $\mathbf{1}$ are within hydrogen bonding distances from the side chains of Lys501, Asn405, Glu49, Ser404 and the main chain nitrogen of Phe90 and one hydroxyl is bridged to a carbonyl oxygen of Ile499 by a water molecule. These interactions underscore the importance of the unique C-terminal region in substrate recognition. The substrate binding site is large enough to accommodate a diiodinated 1 (Supplementary Fig. 35). The substrate binding site is situated relatively close to the protein surface, which could allow access to larger substrates, like resveratrol (23). The halogenation center is nevertheless restricted by the helical C-terminal region to addition of up to two halogens; a trihalogenated product cannot be sterically accommodated and neither can halogenated L-Trp (Supplementary Fig. 33).

Crystal structures of PltM with FAD bound in different states. PltM represents a type of FAD-dependent enzymes, where FAD dissociates out of its binding site for reduction. To gain structural insight into this enigmatic process, we sought to determine a crystal structure of PltM-FAD complex by soaking the crystals of apo PltM with FAD. We obtained two different crystal forms of PltM-FAD complexes, where a molecule of FAD was bound to PltM in two different states (Fig. 4c, d, Supplementary Table 4). In one state, an FAD molecule was bound at a site and orientation analogous to those observed in structures of other FADdependent halogenases, where the isoalloxazine group of the FAD was fully encased by the enzyme (Fig. 4c, Supplementary Fig. 36). A chloride ion was well resolved at a conserved site near the FAD. In the other state, the FAD molecule was bound near the mouth of the FAD binding cleft, with the clearly resolved isoalloxazine ring in the same plane, but oriented perpendicularly to the fully bound state, also making extensive contacts with the protein (Fig. 4d). The electron density for the rest of the FAD molecule is not observed due to disorder (Supplementary Fig. 37), as in this state the adenine nucleotide moiety is directed into the solvent. This structure may represent an intermediate between the apo and the fully bound FAD state. The crystals of PltM-FAD complexes in this state belong to the same crystal form as the crystals of all other complexes in this study; therefore, crystal packing interactions have no effect on the FAD binding state. A short nonconserved loop containing three Ala, a Gly and a Ser (residues 172-178) and the side chain of Gln321 are in two different conformations in these two structures (Fig. 4c, d). In the holoenzyme state, the loop and Gln321 form one side of the narrow cleft holding the adenine nucleotide portion of FAD in place: the side chain of Ala173 interacts with the adenine ring of the FAD, Ala174 interacts with the phosphosugar bridge, and the aliphatic portion of Gln321 holds the riboflavin bridge. In the state with partially bound FAD, this cleft is collapsed, and filled with water. In this state, the isoalloxazine ring is sandwiched between Phe325 and the backbone of loop residues Ala174 and Gln175, including the $\mathrm{C}_{\beta}$ of the latter residue. The FAD binding pocket does not contain $\mathrm{a} \mathrm{Cl}^{-}$, indicating that a halide ion binds upon the final steps of FAD binding. Previous kinetic experiments with $\mathrm{RebH}^{26}$ and $p$-hydroxybenzoate hydroxylase ${ }^{27}$ suggested that kinetically significant conformational changes involving FAD dynamics occurred in FAD recycling. For both enzymes, it was proposed that a distinct mechanistically important state exists where the flavin ring of FAD can undergo redox chemistry, while being sufficiently shielded away from the solvent. This structure may represent such intermediate; future extensive kinetic studies probing the FAD recycling mechanism are needed to address this directly.

Halogenation assays in fermentation culture. As a preliminary assessment of potential use of PltM in a fermentation setting, we tested whether phloroglucinol (1) can be halogenated upon adding it to the culture of Escherichia coli BL21(DE3) overexpressing PltM. We also validated the substrate binding cavity observed in the crystal structures by testing halogenation by two point mutants of PltM, L111Y and S404Y, in this setting. These two residues (one from the FAD binding fold and one from the C-terminal region) line the substrate binding cavity, and their bulkier substitutions are predicted to block binding of 1 (Supplementary Fig. 38). In addition, as negative controls, we used PltM K87A that was demonstrated to be inactive in vitro as well as PltA. All five proteins were expressed at the same level. The cells expressing wild-type PltM generated mono- and dichlorinated 1 (Fig. 5, Supplementary Fig. 39). No halogenated product was observed in cultures expressing PltM K87A and PltA, validating the PltM as the sole source of halogenation activity. For the cells expressing L111Y and S404Y mutants, the product yield was significantly reduced compared to wild-type; the effect of the S404Y mutation was especially severe. We determined a crystal structure of PltM L111Y, which showed that the overall protein structure is unperturbed and the only effect of the mutation was to obstruct the access to the substrate binding pocket, as predicted (Supplementary Fig. 38). S404Y caused a more drastic effect than L111Y because Y404 was predicted to sterically clash with the bound substrate. These data further validated the structure-based definitions of the substrate binding site and suggested a potential for halogenation in a fermentation setting. Future fermentation experiments to maximize the yield of halogenated product will require optimization of the producing host strain and other culture growth conditions.

Kinetics and regiospecificity of PltM in optimized reactions. For quantitative analysis of enzyme kinetics and detailed structural characterization of reaction products, as well as for potential future biotechnological use, we extensively optimized in vitro enzymatic reaction conditions and coupled enzymes to maximize product yield. The critical factors of the optimized conditions were introducing glucose dehydrogenase (GDH) for NADPH regeneration $^{28}$ and lowering the concentrations of NADPH and halide salts. This optimization significantly improved reaction yields, resulting in full conversion of several substrates (Supplementary Table 7). This additional information corroborated the preference for substrates containing electron withdrawing groups and showed preference of PltM for substrates with 1- and 3hydroxyl or amino groups. We determined the halide preference and evaluated quantitatively the kinetics of chlorination and bromination of substrates $\mathbf{3}, \mathbf{1 1}$, and 16, which showed $100 \%$ conversion upon overnight reaction (Table 1 and Supplementary Fig. 40). Kinetic of iodination could not be analyzed quantitatively due to gradual enzyme precipitation in the presence of iodide. These data indicated that PltM preferred chlorination for all substrates that were eventually dichlorinated. The preference for bromination versus iodination depended on particular 

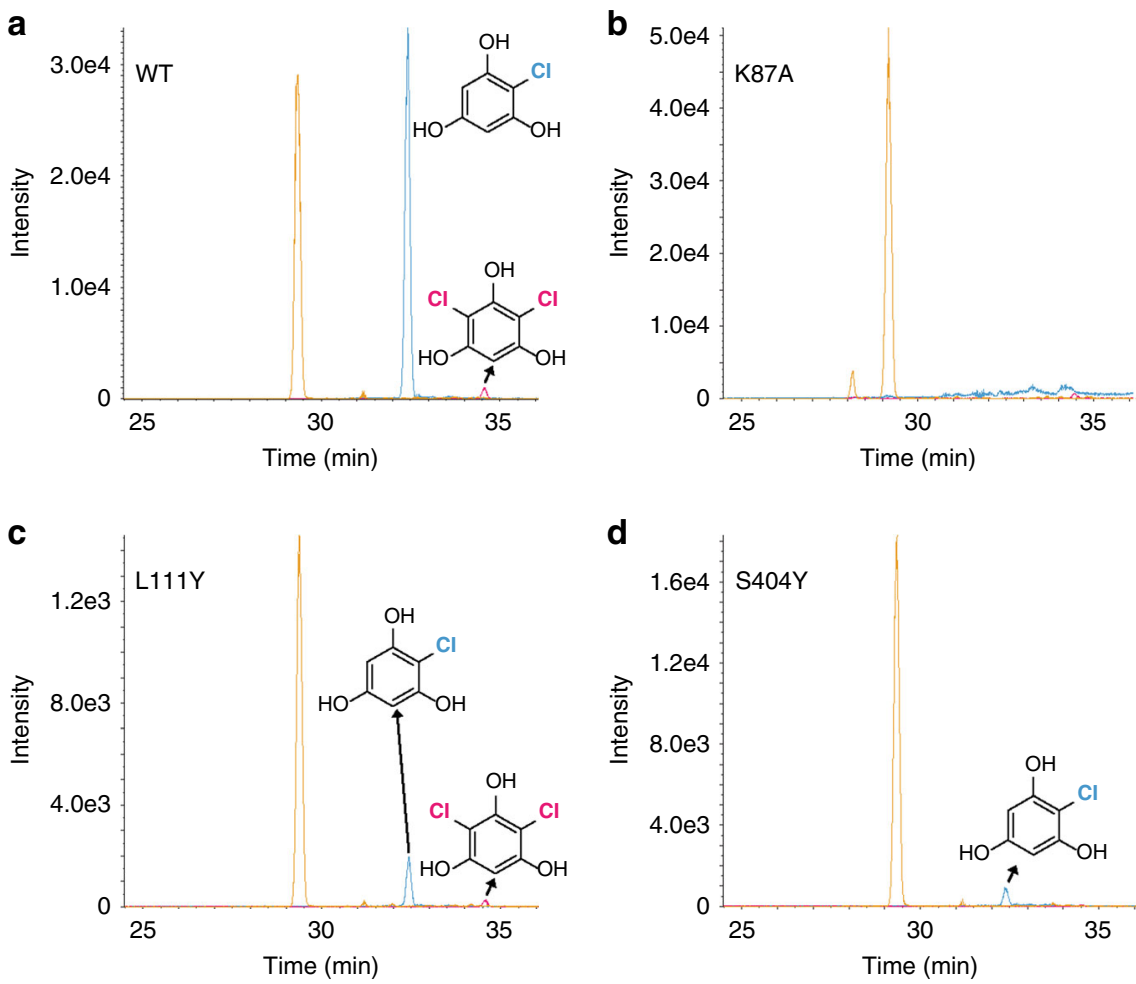

Fig. 5 Halogenation by PItM and its mutants in a cell-based assay. XIC traces of the cell-based halogenation assay using wild-type PItM (a), PItM K87A (b), PItM L111Y (c), and PItM S404Y (d). The blue trace refers to the mono-chlorinated $\mathbf{1}$ while the pink trace shows the dichlorinated $\mathbf{1}$. The orange trace refers to unmodified starting compound $\mathbf{1}$

Table 1 Kinetic parameters for halogenations of selected substrates

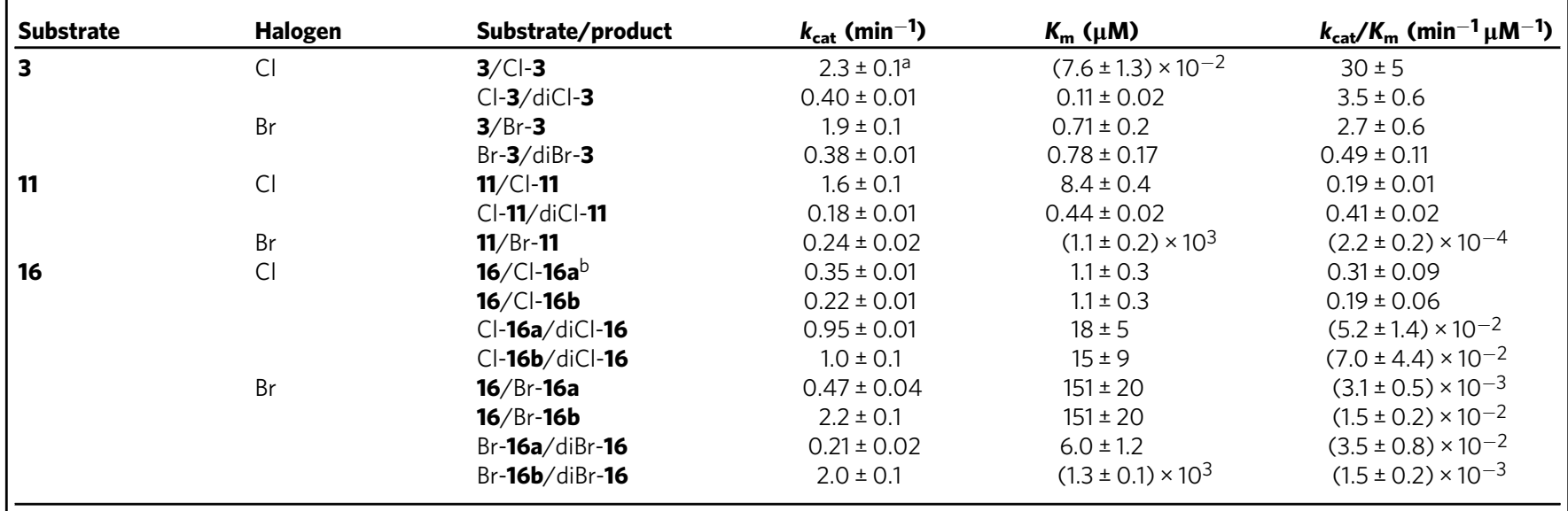

aThe values of all mono-halogenation and dihalogenation rate constants $k_{\mathrm{cat}, 1}$ and $k_{\mathrm{cat}, 2}$, respectively, and $K_{\mathrm{m}}$ for mono-halogenation and dihalogenation $\left(\right.$ defined as $\left(k_{\mathrm{d}, 1}+k_{\mathrm{cat}, 1}\right) / k_{\mathrm{a}, 1}$ and $\left(k_{\mathrm{d}, 2}+k_{\mathrm{cat}, 2}\right) / k_{\mathrm{a}, 2}$, respectively) were determined by nonlinear regression using DynaFit, as described in Methods

bTwo distinct mono-halogenation products of the same reaction are denoted by labels $\mathbf{a}$ and $\mathbf{b}$

substrates, with $\mathbf{3}$ and $\mathbf{1 6}$ showing preference for bromination, and $\mathbf{1 1}$ for iodination. In fact, both $\mathbf{3}$ and $\mathbf{1 6}$ were dibrominated by PltM. Chlorination and bromination of 3 and 16 occurred with similar efficiencies, whereas $\mathbf{1 1}$ was chlorinated much better than brominated or iodinated. Interestingly, two monohalogenated products were observed for iodination of $\mathbf{1 1}$ and for halogenation of 16. No fluorination was still observed for any substrates at the optimized conditions.

The high yield of chlorination and bromination of these and several other compounds allowed us to establish the regiospecificity of the halogenation by PltM. However, some substrates or products were insufficiently stable during halogenation reactions precluding their quantitative structural analysis. We determined the structures of the final dichlorinated products of $3,8,9,11,15$, 16, 18, as well as the monochlorinated product of 23 and the dibrominated product of 3 by NMR spectroscopy. The resulting products were 4,6-diCl-3, 4,6-diCl-8, 2,4-diCl-9, 2,6-diCl-11, 3,5diCl-15, 4,6-diCl-16, 4,6-diCl-18, 4-Cl-23, and 4,6-diBr-3, respectively (Fig. 6 and Supplementary Figs. 42-59). These structures were consistent with the time course experiments showing one mono-halogenated intermediate for symmetrical substrates $\mathbf{3}$ and $\mathbf{1 1}$ and two mono-halogenated intermediates for asymmetrical substrate 16. Likewise, for most other substrates $(\mathbf{8}, \mathbf{1 5}$, and $\mathbf{1 8})$ the structures of the respective monochlorinated 
<smiles>Cc1cc(O)c(Cl)c(O)c1Cl</smiles><smiles>OCc1c(Cl)c(O)cc(O)c1Cl</smiles><smiles>CC(=O)c1c(O)c(Cl)c(O)c(Cl)c1O</smiles><smiles>Nc1cc(O)c(Cl)cc1Cl</smiles><smiles>[14CH3][14CH3]</smiles><smiles>[134CH3][135I]</smiles><smiles>Nc1cc(N)c(Cl)cc1Cl</smiles>

4,6-diCl-18<smiles>Oc1ccc(/C=C/c2cc(O)c(Cl)c(O)c2)cc1</smiles>

Fig. 6 Structures of the products of halogenation by PItM. Structures, as determined by NMR spectroscopy, of products resulting from the halogenation of compounds 3, 8, 9, 11, 15, 16, 18, and 23 by PltM

intermediates are unambiguously inferred owing to the product symmetry. These results show that for mono- or di-hydroxylated or aminated substrates, PltM halogenates almost exclusively in ortho to these polar groups, but not between them. However, when a methyl or a styrene moiety was found in meta to two hydroxyls, as in compound $\mathbf{9}$ (which was dichlorinated) and resveratrol (23; which was monochlorinated), respectively, we observed that a chlorination event occurred between the two hydroxyls.

Development of an immobilized halogenating system. The halogenation yield is limited by the stability of proteins, with PltM being the limiting factor. To achieve a more efficient and scalable halogenation reaction, we developed a method, where all three proteins were immobilized on agarose resin (Affi-Gel ${ }^{\circledR} 15$ ), packed into a spin column and then used as a resin conjugate for halogenation. The halogenation reactions were performed by adding substrate and reagents into the column. This proteinbound resin showed a high halogenation yield for some compounds, which could not be efficiently halogenated by free enzymes in solution (Fig. 7). Notably, the enzyme-resin conjugate could be reused 5-6 times without significant loss of efficiency (Supplementary Fig. 41).

The remarkable halide versatility for any FAD-dependent halogenase and very broad substrate profile for a phenolic halogenase call for future exploration of PltM as a halogenation tool. Our structures revealed a unique architecture of this enzyme, and an FAD orientation that may be relevant to the FAD recycling mechanism shared by FAD binding enzymes.

\footnotetext{
Methods

Materials and instrumentation. The PltM, SsuE, and PltA (used as a control in this study) proteins were overexpressed and purified based on our previously described protocols ${ }^{23,24}$. DNA primers for PCR were purchased from Integrated DNA Technologies (IDT; Coralville, IA, USA). Restriction enzymes, Phusion DNA polymerase, and T4 DNA ligase were purchased from New England BioLabs (NEB; Ipswich, MA, USA). All chemicals and buffer components were purchased from Sigma-Aldrich or VWR (Radnor, PA, USA) and used without any further purification. Size-exclusion chromatography was performed on a fast protein liquid chromatography (FPLC) system BioLogic DuoFlow (Bio-Rad; Hercules, CA, USA) by using a HiPrep 26/60 S-200 HR column (GE Healthcare, Piscataway, NJ, USA). LC-MS was performed on a Shimadzu high-performance liquid chromatography (HPLC) system equipped with a DGU-20A/3R degasser, LC-20AD binary pumps, a CBM-20A controller, a SIL-20A/HT autosampler (Shimadzu, Kyoto, Japan), and Vydac HPLC DENALI ${ }^{\text {mm }}$ Column $\left(\mathrm{C}_{18}, 250 \times 4.6 \mathrm{~mm}, 5 \mu \mathrm{m}\right.$ particle size $)$ from Grace (Columbia, MD, USA) and an AB SCIEX TripleTOF 5600 (AB SCIEX,
}
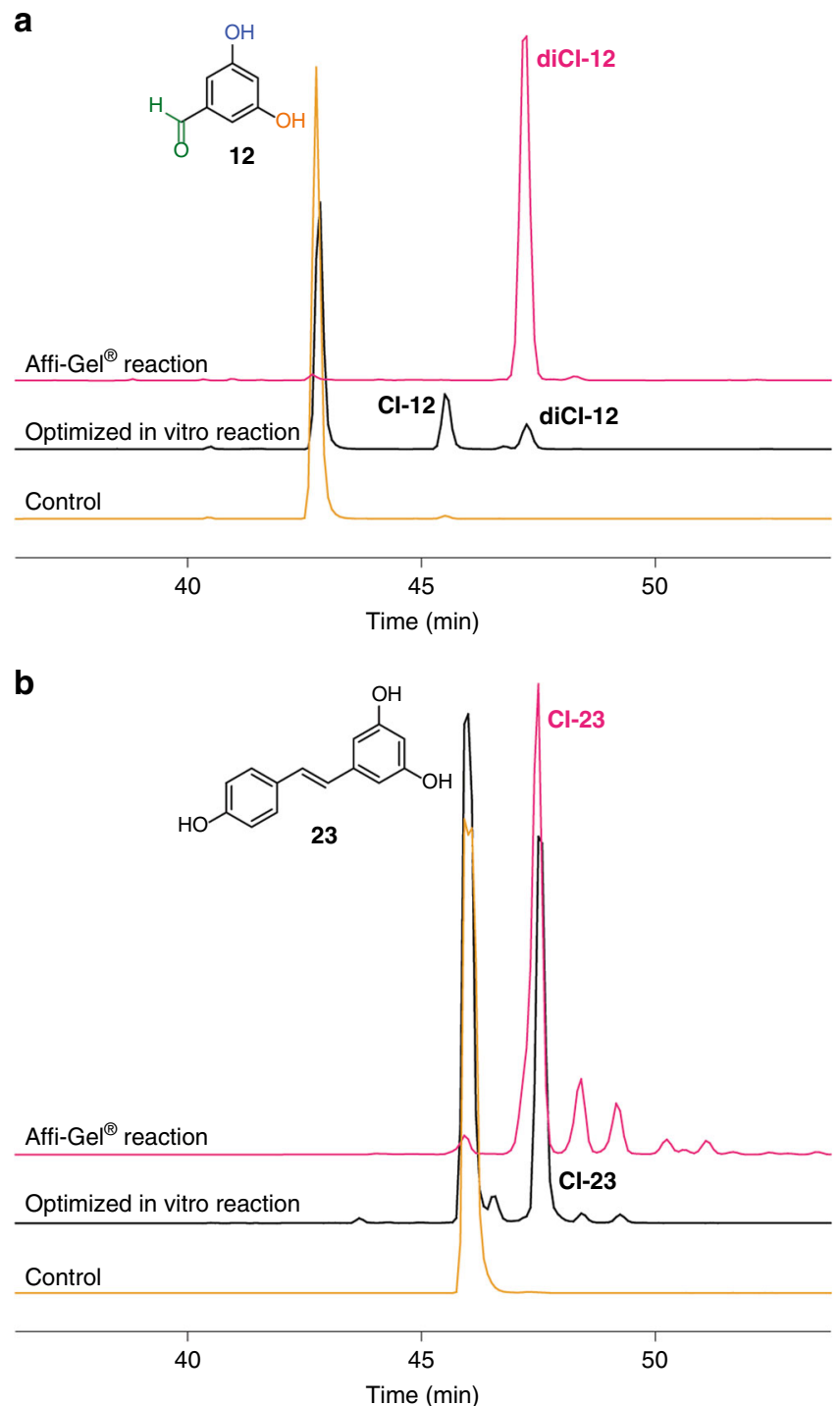

Fig. 7 HPLC chromatograms of chlorination reactions by PltM with substrates. Reaction with $\mathbf{a} \mathbf{1 2}$ and $\mathbf{b} \mathbf{2 3}$ prior (black traces) and after optimization employing Affi-Gel ${ }^{\circledR}$ resin (pink traces)

Redwood City, CA) mass spectrometer recording in negative or positive mode between 80 and $600 \mathrm{~m} / z$. HPLC was performed on an Agilent Technologies 1260 Infinity system equipped with a Vydac HPLC DENALI ${ }^{\mathrm{TN}}$ column $\left(\mathrm{C}_{18}\right.$, $250 \times 4.6 \mathrm{~mm}, 5 \mu \mathrm{m}$ particle size $)$ and an Alltech Econosil HPLC column $\left(\mathrm{C}_{18}\right.$, $250 \times 10 \mathrm{~mm}, 10 \mu \mathrm{m}$ particle size; Grace) for analytical and semi-preparative experiments, respectively. ${ }^{1} \mathrm{H}$ and ${ }^{13} \mathrm{C}$ NMR spectra were recorded at 400 and 500 (for ${ }^{1} \mathrm{H}$ ) as well as $100 \mathrm{MHz}$ (for ${ }^{13} \mathrm{C}$ ) on Varian 400 and $500 \mathrm{MHz}$ spectrometers, using deuterated solvents as specified. Chemical shifts $(\delta)$ are given in parts per million (ppm). Coupling constants $(J)$ are given in Hertz $(\mathrm{Hz})$, and conventional abbreviations used for signal shape are as follows: s, singlet; $d$, doublet; $t$, triplet; $m$, multiplet; q, quartet.

Synthesis of compound 15. Aluminum chloride ( $1.3 \mathrm{~g}, 9.99 \mathrm{mmol})$ was slowly added to a solution of phloroglucinol $(1,315 \mathrm{mg}, 2.50 \mathrm{mmol})$ in 1:1/1,2-dichloroethane:nitrobenzene $(10 \mathrm{~mL})$ at $0{ }^{\circ} \mathrm{C}$. After stirring this mixture at this temperature for $10 \mathrm{~min}$ under a nitrogen atmosphere, acetyl chloride $(0.21 \mathrm{~mL}, 3.00 \mathrm{mmol})$ was added. Then the ice bath was removed, and the mixture was stirred at $80^{\circ} \mathrm{C}$ for $2 \mathrm{~h}$. The reaction progress was monitored by TLC (1:2/EtOAc:Hexanes, $\left.R_{f} 0.35\right)$. The reaction mixture was quenched with $\mathrm{H}_{2} \mathrm{O}(60 \mathrm{~mL})$, extracted with EtOAc $(2 \times$ $100 \mathrm{~mL}$ ), washed with brine $(20 \mathrm{~mL})$, and then dried over $\mathrm{MgSO}_{4}$. The organic layer was removed under reduced pressure and the residue was purified by flash column chromatography ( $\mathrm{SiO}_{2}, 1: 2 /$ EtOAc:Hexanes) to afford the known compound $15^{30}(223 \mathrm{mg}, 53 \%)$ as a yellow solid: ${ }^{1} \mathrm{H}$ NMR $\left(400 \mathrm{MHz}, \mathrm{CD}_{3} \mathrm{OD}\right) \delta 5.78$ (s, $2 \mathrm{H}), 2.58(\mathrm{~s}, 3 \mathrm{H}) ;{ }^{13} \mathrm{C} \mathrm{NMR}\left(100 \mathrm{MHz},\left(\mathrm{CD}_{3}\right)_{2} \mathrm{SO}\right) \delta 203.1,164.9,164.5,104.2$, 94.1, 31.3. 
PItM mutagenesis. PltM mutants K87A, L111Y, and S404Y were constructed by splicing-by-overlap-extension method ${ }^{31}$. The sequences downstream and upstream of the mutation site were amplified first individually from pplt $M$-pET28a(NHis). For PltM K87A mutant; the primer pairs were \#1: 5'-CGCCTGCGGGATCgcgCT GGGCTTCAGTTTTG-3' with \#2: 5' -CATACTCGAGCTAGACTTTGAGGATGA AACGATTG-3' and \#3: 5'-CAAAACTGAAGCCCAGcgcGATCCCGCAGGCG-3' with \#4: 5'-GCAGCTCTCATATGAATCAGTACGACGTCATTATC-3'. For PltM L111Y mutant; the primers were \#5: 5'-CTTGTGGCCCCGCCGtatAAGGTGCCG GAAGCC- 3 ' with \#2 and \#6: $5^{\prime}$-GGCTTCCGGCACCTTataCGGCGGGGCCACA AG-3' with \#4. For PltM S404Y mutant, the primer pairs were \#7: 5'-CTGGCTC AGCGGCtatAACCTGGGCAGTGC- $3^{\prime}$ with \#2 and \#8: $5^{\prime}$-GCACTGCCCAGGTTataGCCGCTGAGCCAG- $3^{\prime}$ with \#4. The PCR products of the above primer pairs were used as templates for another round of PCR using primers \#2 and \#4. The products from the second round of PCR were digested with restriction enzymes NdeI and XhoI and ligated into NdeI/XhoI-linearized pET28a, yielding ppltMK87A-pET28a, ppltML111Y-pET28a, and ppltMS404Y-pET28a. The mutations were verified by DNA sequencing (Eurofins Genomics).

Preparation of pgdh-pET28a overexpression construct. The glucose dehydrogenase $(g d h)$ gene was amplified from genomic DNA of Bacillus subtilis subsp. subtilis 168 by PCR with the forward and reverse primers: $5^{\prime}$-AGGATGCATATG TATCCGGATTTAAAAGGAAAAG- ${ }^{\prime}$ and $5^{\prime}$-CGCTTTCTCGAGTTAACCGCG GCCTGCCTGGAAT-3', respectively. The PCR product was purified by agarose gel extraction and digested by restriction enzymes NdeI and XhoI, which was subsequently ligated into NdeI/XhoI-linearized pET28a. The resulting plasmid pgdh-pET28a was transformed into a chemically competent E. coli TOP10 strain, and the cloning was verified by sequencing of the purified plasmids.

\section{Preparation of PItM and coupled enzymes for in vitro assays. Open reading} frames encoding PltM and FAD reductase SsuE were cloned into E. coli expression vectors as previously reported ${ }^{23}$. For the production of PltM, SsuE, and GDH, the expression vectors were transformed into E. coli BL21(DE3) (ATCC; Manassas, VA). In each case, a colony was grown overnight at $37^{\circ} \mathrm{C}$ with shaking at $200 \mathrm{rpm}$ in LB medium $(5 \mathrm{~mL})$ supplemented with $50 \mu \mathrm{g} / \mathrm{mL}$ kanamycin. These overnight cultures were inoculated into LB medium $(1 \mathrm{~L})$ supplemented with $50 \mu \mathrm{g} / \mathrm{mL}$ kanamycin. Cultures were grown $\left(37^{\circ} \mathrm{C}, 200 \mathrm{rpm}\right)$ until an attenuance at $600 \mathrm{~nm}$ of 0.6 was reached. At this time, protein expression was induced by adding isopropyl$\beta$-D-1-thiogalactopyranoside (IPTG, $0.2 \mathrm{mM}$ ), and the cultures were incubated at $16{ }^{\circ} \mathrm{C}$ with shaking at $200 \mathrm{rpm}$ for an additional $20 \mathrm{~h}$. The cells were harvested by centrifugation at $3000 \times g$ for $10 \mathrm{~min}$ at $4{ }^{\circ} \mathrm{C}$. The cell pellets were washed with buffer A ( $50 \mathrm{mM}$ sodium phosphate $\mathrm{pH} 7.4,400 \mathrm{mM} \mathrm{NaCl}, 5 \mathrm{mM}$ imidazole, and $10 \%$ glycerol). The cells were resuspended in $40 \mathrm{~mL}$ of buffer A supplemented with $1 \mathrm{mM}$ dithiothreitol (DTT) and $1 \mathrm{mM}$ phenylmethanesulfonyl fluoride (PMSF). The cells were then lysed by intermittent sonication, followed by clarification by centrifugation at $40,000 \times g$ for $45 \mathrm{~min}$ at $4{ }^{\circ} \mathrm{C}$. The supernatants were incubated with $0.5 \mathrm{~mL}$ of pre-washed $\mathrm{Ni}^{\mathrm{II}}$-NTA agarose resin (Qiagen, Valencia, CA) at $4{ }^{\circ} \mathrm{C}$ for $2 \mathrm{~h}$ with slow tumbling. The slurry was loaded onto a column and washed with $2 \times 5 \mathrm{~mL}$ of buffer A followed by elution with a gradient of imidazole concentration in buffer A $(2 \times 5 \mathrm{~mL}$ of $20 \mathrm{mM}, 5 \mathrm{~mL}$ of $40 \mathrm{mM}, 5 \mathrm{~mL}$ of $60 \mathrm{mM}, 2 \times 5 \mathrm{~mL}$ of 250 $\mathrm{mM})$. Fractions containing pure proteins were combined and dialyzed against $3 \times$ $2 \mathrm{~L}$ of buffer $\mathrm{B}(50 \mathrm{mM}$ sodium phosphate $\mathrm{pH} 7.4,2 \mathrm{mM} \beta$-mercaptoethanol ( $\beta \mathrm{ME})$, and $10 \%$ glycerol). Each of the three dialysis steps was performed at least for $4 \mathrm{~h}$. The dialyzed proteins were concentrated to $\sim 20 \mathrm{mg} / \mathrm{mL}$ for PltM and GDH or $\sim 2.5 \mathrm{mg} / \mathrm{mL}$ for SsuE by using Amicon Ultra-15 Centrifugal Filter Units (EMD Millipore, Billerica, MA, USA) with 10-kDa molecular weight cutoff (MWCO) for $\mathrm{PltM}$ and GDH or $3-\mathrm{kDa}$ MWCO for SsuE, and protein concentrations were determined by absorbance at $280 \mathrm{~nm}$ with calculated extinction coefficients $\varepsilon=$ $59,840,20,340$, and $29,910 \mathrm{M}^{-1} \mathrm{~cm}^{-1}$ for PltM, SsuE, and GDH, respectively (http://protcalc.sourceforge.net/cgi-bin/protcalc). The total yields of pure PltM, SsuE, and GDH were $17.6,6.0$, and $10.3 \mathrm{mg}$ from $1 \mathrm{~L}$ of culture, respectively. The proteins were flash frozen in liquid nitrogen and stored at $-80^{\circ} \mathrm{C}$ for biochemical assays. The point mutants of PltM were purified by using the above protocol for the full-length PltM.

Preparation of PItM for crystallography. Wild-type PltM and PltM L111Y mutant were purified as described above with an additional size-exclusion chromatography step. Wild-type PltM and PltM L111Y eluted from $\mathrm{Ni}^{\mathrm{II}}$ resin were loaded onto an S-200 column equilibrated in $40 \mathrm{mM}$ Tris- $\mathrm{HCl}, \mathrm{pH}$ 8.0, $100 \mathrm{mM}$ $\mathrm{NaCl}, 2 \mathrm{mM} \beta \mathrm{ME}$. Fractions containing $\mathrm{NHis}_{6}$-PltM were pooled and concentrated to $40 \mathrm{mg} / \mathrm{mL}$ by using an Amicon Ultra-15 Centrifugal Filter Unit with $10 \mathrm{kDa}$ MWCO. Purified PltM proteins were kept on ice for crystallization studies.

In vitro assays of PItM with various substrates and halides. The halogenation assays were carried out similarly to a recently described procedure ${ }^{22}$. The substrates that have been tested are given in Fig. 3a and Supplementary Fig. 7.

For substrate profile determination (Assay 1), $100 \mu \mathrm{L}$ reactions were carried out in $30 \mathrm{mM}$ sodium phosphate $\mathrm{pH}$ 7.4. As a halide source, we used $200 \mathrm{mM}$ of either $\mathrm{NaF}$ (Assay 1a), $\mathrm{NaCl}$ (Assay 1b), $\mathrm{NaBr}$ (Assay 1c), or NaI (Assay 1d). To ensure that PltM is incapable of fluorinating, an additional $200 \mu \mathrm{L}$ reaction with $300 \mathrm{mM}$
$\mathrm{NaF}$ was run. We also ran $200 \mu \mathrm{L}$ reaction with $400 \mathrm{mM} \mathrm{NaBr}$ to ensure no additional bromination reaction occurred. Each reaction also contained a specified substrate $(0.5 \mathrm{mM})$, FAD $(0.2 \mathrm{mM})$, NADPH $(5 \mathrm{mM})$, PltM $(5.5 \mu \mathrm{M})$, and SsuE $(5.0 \mu \mathrm{M})$. The reactions were initiated by adding NADPH under $\mathrm{N}_{2}$. The reaction tubes were tightly closed to avoid contact with air. The reaction mixtures were incubated at $25^{\circ} \mathrm{C}$ for $3 \mathrm{~h}$ prior to extraction with EtOAc $(4 \times 100 \mu \mathrm{L})$. The organic layer was dried by a gentle flow of air, and the residue was dissolved in $\mathrm{MeOH}$ to prepare $1-10 \mu \mathrm{g} / \mathrm{mL}$ samples for LC-MS analysis.

To establish if hetero-dihalogenation by PltM could be observed, halogenating competition assays in 1:1 or 10:1 mixture of two different halide salts were performed (Assay 2). The reactions contained the same components as above except single halide salts were replaced with either a 1:1/NaCl: $\mathrm{NaBr}$ (Assay 2a), 1:1/NaCl:NaI (Assay 2b), or 1:1/NaBr:NaI (Assay 2c) mixtures (100 mM of each halide). The reactions were initiated by adding NADPH under $\mathrm{N}_{2}$. A 1:1/NaCl: $\mathrm{NaBr}$ reaction was also performed with $200 \mathrm{mM}$ of each halide to test the occurrence of homo-di- or hetero-chlorination/bromination, and 10:1/NaCl:NaI (Assay 2d) and 10:1/NaBr:NaI (Assay 2e) mixtures with $200 \mathrm{mM}$ of $\mathrm{NaCl}$ or $\mathrm{NaBr}$ and $20 \mathrm{mM}$ of NaI were tested to check whether chlorination or bromination could occur in the presence of iodide and whether iodination can occur with chlorination or bromination to yield a $\mathrm{Cl}, \mathrm{I}$-substrate or $\mathrm{Br}, \mathrm{I}$-substrate. The reactions were incubated and processed as described above in Assay 1.

Optimized in vitro PItM halogenation assay. To increase the production of halogenated molecules and decrease the amount of NADPH required, the above in vitro assay was optimized by using an additional enzyme, $\mathrm{GDH}^{28}$. The optimized reaction mixture contained substrate $(0.5 \mathrm{mM}$ for chlorination and bromination; $0.25 \mathrm{mM}$ for iodination; prepared from $50 \mathrm{mM}$ stock in DMSO), FAD (5 $\mu \mathrm{M})$, NADPH $(5 \mu \mathrm{M})$, PltM $(6 \mu \mathrm{M})$, SsuE $(5 \mu \mathrm{M}), \mathrm{GDH}(0.5 \mu \mathrm{M})$, glucose $(20$ $\mathrm{mM}), \mathrm{NaX}$ (10 mM for chlorination and bromination; $0.5 \mathrm{mM}$ for iodination), and sodium phosphate $(30 \mathrm{mM}, \mathrm{pH} 7.4)$, and was incubated at room temperature. The overall yield of halogenation products was determined for reactions run overnight for several substrates (Supplementary Table 7). Conversion of the substrate to halogenated products was monitored by HPLC at $\lambda=275-320 \mathrm{~nm}$, where the absorbance of molecules is not affected by halogenation, and quantified as fraction of reaction species (\%). The time course experiments for kinetic analysis were performed in $100 \mu \mathrm{L}$ reaction mixtures by quenching the reactions at $0,5,15,30$, $60,120,240$, and $360 \mathrm{~min}$ (for 3 and 16), and an additional $720 \mathrm{~min}$ (for 11) for chlorination and bromination, and at $0,30,60,120,240$, and $480 \mathrm{~min}$ (for 3 and 16), or an additional $720 \mathrm{~min}$ (for 11) for iodination. The time course experiments were performed in duplicate. Compound $\mathbf{1}$ was unstable under these optimized conditions, and it was not tested. The in vitro analysis of K87A mutant was performed overnight in $100 \mu \mathrm{L}$ reaction mixture by using compound $\mathbf{1 1}$ as a substrate. Wild-type PltM was used as a positive control, and no enzyme reaction was used as a negative control. In all the above reactions, the compounds were extracted with EtOAc $(4 \times 100 \mu \mathrm{L})$ and dried under gentle air flow. The products were dissolved in $\mathrm{MeOH}$ ( $30 \mu \mathrm{L}$ for chlorination and bromination; $15 \mu \mathrm{L}$ for iodination) for HPLC analysis. The scale-up experiments were performed overnight in $25 \mathrm{~mL}$ for compound 23 , in $50 \mathrm{~mL}$ for compounds $\mathbf{3}, \mathbf{8}, \mathbf{9}, \mathbf{1 1}, \mathbf{1 5}$, and $\mathbf{1 8}$, or $100 \mathrm{~mL}$ for 16 . PltM concentration was $25 \mu \mathrm{M}$ with compounds 15 and $250 \mu \mathrm{M}$ with compound 23. To process the chlorination reaction of compound 23, ice-cold $\mathrm{MeOH}(50 \mathrm{~mL})$ was added to precipitate the proteins. This mixture was incubated for $2 \mathrm{~h}$ at $-20^{\circ} \mathrm{C}$, and the protein precipitate was removed by centrifugation $\left(40,000 \times g, 30 \mathrm{~min}, 4^{\circ} \mathrm{C}\right)$. The pellet was washed by ice-cold $\mathrm{MeOH}(50 \mathrm{~mL})$ and centrifuged down again $\left(40,000 \times g, 15 \mathrm{~min}, 4^{\circ} \mathrm{C}\right)$. The supernatant was combined in a round-bottomed flask, and $\mathrm{MeOH}$ was removed in vacuo. The products were extracted with EtOAc $(4 \times$ reaction volume $)$ and dried in vacuo. These were dissolved in $\mathrm{MeOH}(0.5-1 \mathrm{~mL})$ for purification by semi-preparative HPLC.

Halogenation assay using immobilized enzymes. To increase the yield of halogenation reaction and make the enzymes reusable, PltM, SsuE, and GDH, we immobilized these proteins on Affi-Gel ${ }^{\oplus} 15$ resin (Bio-Rad, Hercules, CA). To increase the stability of the coupled enzymes, GDH from Bacillus amyloliquefaciens SB5 (GDH-BA) ${ }^{32}$ was used in this assay. This enzyme was expressed and purified, as described above, from a pET23a vector $\left(a m p^{\mathrm{R}}\right)$ containing a synthetic gene encoding this enzyme (NCBI accession \#JQ305165) with an $\mathrm{NHis}_{6}$ tag, purchased from GenScript (Piscataway, NJ). The enzymes were dialyzed into buffer $\mathrm{C}$, which contains HEPES (50 mM, pH 7.5), $\beta$ ME ( $2 \mathrm{mM})$, and glycerol (10\%). Suspended Affi-Gel $^{\circledR}$ resin $(250 \mu \mathrm{L})$ was transferred into a QIAquick spin column (Qiagen), and the resin was washed three times with $500 \mu \mathrm{L}$ of $\mathrm{H}_{2} \mathrm{O}$ and buffer D $(30 \mathrm{mM}$ HEPES, pH 7.5). For each time, the wash solution was removed by centrifugation $\left(400 \times g\right.$, for $\left.15-30 \mathrm{~s}, 4^{\circ} \mathrm{C}\right)$. The washed resin was incubated with SsuE $(\sim 50 \mu \mathrm{M}$, $300 \mu \mathrm{L})$ for $4 \mathrm{~h}$ at $4{ }^{\circ} \mathrm{C}$. The beads were washed with buffer D twice and subsequently incubated with a mixture of GDH-BA $(\sim 200 \mu \mathrm{M}, 50 \mu \mathrm{L})$ and PltM $(\sim 500$ $\mu \mathrm{M}, 250 \mu \mathrm{L}$ ) overnight at $4^{\circ} \mathrm{C}$. This resin-enzyme conjugate was washed twice with buffer $\mathrm{D}$ and preserved in $4^{\circ} \mathrm{C}$ in buffer D until needed. For each $250 \mu \mathrm{L}$ resin, 300 $\mu \mathrm{L}$ of reaction solution, which contained substrate $(0.5 \mathrm{mM}), \mathrm{FAD}(5 \mu \mathrm{M}), \mathrm{NADPH}$ $(5 \mu \mathrm{M})$, glucose $(20 \mathrm{mM}), \mathrm{NaCl}(10 \mathrm{mM})$, and HEPES (30 mM, pH 7.5), was used. The reaction with resveratrol (23) was performed overnight at room temperature The reaction solution was collected by centrifugation $(400 \times g$, every $15-30 \mathrm{~s}$ until the solution was removed, $\left.4^{\circ} \mathrm{C}\right)$, and the resin-enzyme conjugate in the column 
was washed with buffer $\mathrm{D}(300 \mu \mathrm{L})$ three times. These solutions were extracted with EtOAc $(4 \times 300 \mu \mathrm{L})$ and dried in vacuo. The solid material was dissolved in $\mathrm{MeOH}$ $(200 \mu \mathrm{L})$ and analyzed by HPLC (Fig. 7). The reusability of the resin-enzyme conjugate was tested with substrates 3 and 11 (Supplementary Fig. 41). The reactions (same as above) were run for $1 \mathrm{~h}$ at room temperature and processed as described above. After processing the reaction, the same reaction was repeated four more times. After the 5 th reaction, the beads were stored at $4{ }^{\circ} \mathrm{C}$ overnight in buffer D. The 6 th-10th reactions were performed in the following day.

Kinetic analysis of PItM halogenation. To determine the halogenation preference, the kinetic parameters were obtained by the global nonlinear regression analysis of all reaction species using DynaFit software ${ }^{29}$ for the following halogenation mechanism:

$$
\begin{gathered}
k_{a, 1} \\
E+S \underset{k_{d, 1}}{\rightleftarrows} E \cdot S \\
E \cdot S \stackrel{k_{\text {cat, } 1}}{\longrightarrow} E \cdot P_{1} \\
E P_{1}+S \stackrel{k_{a, 2}}{\rightleftarrows} E P_{1} \cdot S \\
k_{d, 2} \\
E P_{1} \cdot S \stackrel{k_{\text {cat }, 2}}{\longrightarrow} E+P_{2}
\end{gathered}
$$

where $E, S, P_{1}$, and $P_{2}$ are enzyme, substrate, mono-, and dihalogenated product, respectively.

Cell-based activity assay of PItM. E. coli BL21(DE3) cells were transformed with ppltM-pET28a, ppltMK87A-pET28a, ppltML111Y-pET28a, ppltMS404Y-pET28a, and ppltA-pET28a. The ppltA-pET28a plasmid overexpressing the halogenase PltA whose substrate is pyrrolyl-S-PltL (a peptidyl carrier protein-linked pyrrole) was used as a negative control ${ }^{23}$. Five colonies from each transformant were cultured in $2 \times 500 \mathrm{~mL}$ of LB medium (for ppltM-pET28a, ppltML111Y-pET28a, and ppltMS404Y-pET28a) and $1 \times 500 \mathrm{~mL}$ of LB medium (for ppltMK87A-pET28a and ppltA-pET28a) with $50 \mu \mathrm{g} / \mathrm{mL}$ kanamycin at $37^{\circ} \mathrm{C}$ and $200 \mathrm{rpm}$ until attenuance of 0.2 at $600 \mathrm{~nm}$. The cultures were then moved to $25^{\circ} \mathrm{C}$ until attenuance of 0.5 . Protein expression was induced by adding $0.2 \mathrm{mM}$ IPTG to all seven flasks, and the cultures were incubated with shaking for $1 \mathrm{~h} .12 .5 \mu \mathrm{g} / \mathrm{mL}$ of compound 1 was added to $1 \times 500 \mathrm{~mL}$ of LB medium containing ppltM-pET28a, ppltMK87ApET28a, ppltML111Y-pET28a, ppltMS404Y-pET28a, and ppltA-pET28a. Compound $\mathbf{1}$ was not added to the three remaining flasks (negative controls). After additional incubation for $20 \mathrm{~h}$, the cells were pelleted at $5000 \times \mathrm{g}$ for $10 \mathrm{~min}$, and the supernatant was collected. The supernatant was extracted with EtOAc $(3 \times 330$ $\mathrm{mL})$, which was dried in vacuo. This was then dissolved in $\mathrm{MeOH}(100 \mu \mathrm{L})$ prior to addition of $\mathrm{H}_{2} \mathrm{O}(800 \mu \mathrm{L})$ followed by centrifugation at $20,000 \times \mathrm{g}$ for $10 \mathrm{~min}$ to remove the precipitate. The supernatant was collected and $1 \mu \mathrm{L}$ was diluted into $199 \mu \mathrm{L}$ of MeOH for LC-MS analysis (Supplementary Table 6).

HPLC and LC-MS analysis of halogenated products. The halogenation reaction products were analyzed by HPLC or LC-MS by injecting $10 \mu \mathrm{L}$ of each sample. The compounds were separated by reversed-phase HPLC at the flow rate of $0.2 \mathrm{~mL} / \mathrm{min}$ by using the following program: eluent $\mathrm{A}=\mathrm{H}_{2} \mathrm{O}$; eluent $\mathrm{B}=$ MeCN; gradient $=2 \%$ B for $5 \mathrm{~min}$, increase to $100 \%$ B over a $30 \mathrm{~min}$ period, stay at $100 \% \mathrm{~B}$ for $9 \mathrm{~min}$, decrease to $2 \% \mathrm{~B}$ over a $1 \mathrm{~min}$ period, and re-equilibrate the column at $2 \% \mathrm{~B}$ for 30 $\mathrm{min}$. For HPLC analysis, the molecules were observed by absorbance at $\lambda=275 \mathrm{~nm}$ as described above. As necessary, the following mass spectrometer was operated in negative and positive modes with the following parameters: for negative mode, mass range, $80-600 \mathrm{~m} / z$ in profile mode; temperature, $550^{\circ} \mathrm{C}$ and ion spray voltage floating, $-4500 \mathrm{~V}$, and for positive mode, mass range, $80-600 \mathrm{~m} / \mathrm{z}$ in profile mode; temperature, $550^{\circ} \mathrm{C}$ and ion spray voltage floating, $4500 \mathrm{~V}$. The presence of each compound was analyzed by extracted ion chromatograph (XIC) with the expected mass $\pm 0.05 \mathrm{Da}$ for Assay 1 and Assay 2 and $\pm 0.005 \mathrm{Da}$ for Assay 3 (Fig. 2a-c, Supplementary Figs. 1-6 and 10-30, and Supplementary Tables 2, 3, and 6). The LC-MS was operated by Analyst TF Software (SCIEX, Framingham, MA), and the data was analyzed by PeakView (SCIEX). To purify 4 selected scaled-up halogenated products, semi-preparative HPLC was performed by injecting $100 \mu \mathrm{L}$ per injection at $1 \mathrm{~mL} / \mathrm{min}$ by using the following gradient program with eluent $\mathrm{A}$ as $\mathrm{H}_{2} \mathrm{O}$ (with $0.1 \%$ TFA) (for compounds 3 and 11) or $10 \mathrm{mM}$ ammonium bicarbonate (for 16) and eluent B as MeCN: $2 \%$ B for $10 \mathrm{~min}$, increase to $100 \%$ B over a $40 \mathrm{~min}$ period, stay at $100 \% \mathrm{~B}$ for $5 \mathrm{~min}$, decrease to $2 \% \mathrm{~B}$ over a $1 \mathrm{~min}$ period, followed by re-equilibration in $2 \% \mathrm{~B}$ for $9 \mathrm{~min}$. The collected peak fractions were dried under reduced pressure and lyophilized for NMR analysis.

NMR analysis of products of large-scale halogenation. The exact position for the various halogenations was determined either by comparison with commercially available standards (4,6-dichlororesorcinol) or by a combination of HMBC and HSQC experiments.

The analysis of halogenation products is presented as follows.

Analysis of 4,6-dichlororesorcinol (4,6-diCl-3): ${ }^{1} \mathrm{H}$ NMR $\left(500 \mathrm{MHz}, \mathrm{CD}_{3} \mathrm{OD}\right.$,

Supplementary Fig. 42) $\delta 7.17$ (s, 1H), $6.52(\mathrm{~s}, 1 \mathrm{H})$.

Analysis of 4,6-dibromoresorcinol (4,6-diBr-3): ${ }^{1} \mathrm{H}$ NMR $\left(500 \mathrm{MHz}, \mathrm{CD}_{3} \mathrm{OD}\right.$,

Supplementary Fig. 43) $\delta 7.45(\mathrm{~s}, 1 \mathrm{H}), 6.53(\mathrm{~s}, 1 \mathrm{H}) ;{ }^{13} \mathrm{C} \mathrm{NMR}\left(100 \mathrm{MHz}, \mathrm{CD}_{3} \mathrm{OD}\right.$

Supplementary Fig. 44) $\delta$ 154.1, 134.8, 103.5, 99.3.

Analysis of 2,4,6-trichlororesorcinol (4,6-diCl-8): ${ }^{1} \mathrm{H}$ NMR $\left(500 \mathrm{MHz}, \mathrm{CD}_{3} \mathrm{OD}\right.$, Supplementary Fig. 45) $\delta 7.23(\mathrm{~s}, 1 \mathrm{H})$.

Analysis of 2,4-dichloro-5-methylresorcinol (2,4-diCl-9): ${ }^{1} \mathrm{H}$ NMR $(500 \mathrm{MHz}$, $\mathrm{CD}_{3} \mathrm{OD}$, Supplementary Fig. 46) $\delta 6.43(\mathrm{q}, J=0.5 \mathrm{~Hz}, 1 \mathrm{H}), 2.39(\mathrm{~d}, J=0.5 \mathrm{~Hz}, 3 \mathrm{H})$; ${ }^{13} \mathrm{C}$ NMR (100 MHz, $\mathrm{CD}_{3} \mathrm{OD}$, Supplementary Fig. 47$) \delta 151.9,134.6,112.0,110.0$, $101.3,16.5$

Analysis of 2,6-dichloro-3,5-dihydroxybenzyl alcohol (2,6-diCl-11): ${ }^{1} \mathrm{H}$ NMR $\left(500 \mathrm{MHz}, \mathrm{CD}_{3} \mathrm{OD}\right.$, Supplementary Fig. 48$) \delta 6.55(\mathrm{~s}, 1 \mathrm{H}), 4.85(\mathrm{~s}, 2 \mathrm{H}) ;{ }^{13} \mathrm{C} \mathrm{NMR}$ $\left(100 \mathrm{MHz}, \mathrm{CD}_{3} \mathrm{OD}\right.$, Supplementary Fig. 49$) \delta 152.3,136.2,112.8,103.4,58.9$. The HMBC for 2,6-dichloro-3,5-dihydroxybenzyl alcohol is presented in Supplementary Fig. 50.

Analysis of 3,5-dichloro-2,4,6-trihydroxyacetophenone (3,5-diCl-15): ${ }^{1} \mathrm{H}$ NMR (500 MHz, $\mathrm{CD}_{3} \mathrm{OD}$, Supplementary Fig. 51) $\delta 2.69(\mathrm{~s}, 3 \mathrm{H})$.

Analysis of 5-amino-2,4-dichlorophenol (2,4-diCl-16): ${ }^{1} \mathrm{H}$ NMR $(400 \mathrm{MHz}$, $\mathrm{CD}_{3} \mathrm{OD}$, Supplementary Fig. 52) $\delta 7.06$ (s, 1H), $6.38(\mathrm{~s}, 1 \mathrm{H}) ;{ }^{13} \mathrm{C}$ NMR $(100 \mathrm{MHz}$, $\mathrm{CD}_{3} \mathrm{OD}$, Supplementary Fig. 53) $\delta 152.4,143.8,128.7,109.4,108.7,102.8$. The HSQC and HMBC for 5-amino-2,4-dichlorophenol are presented in Supplementary Figs. 54 and 55, respectively.

Analysis of 2,4-dichloro-1,5-diaminobenzene (2,4-diCl-18): ${ }^{1} \mathrm{H}$ NMR $(500$ $\mathrm{MHz}, \mathrm{CD}_{3} \mathrm{OD}$, Supplementary Fig. 56) $\delta 7.04(\mathrm{~s}, 2 \mathrm{H}) ;{ }^{13} \mathrm{C} \mathrm{NMR}(100 \mathrm{MHz}$, $\mathrm{CD}_{3} \mathrm{OD}$, Supplementary Fig. 57) $\delta 142.8,128.3,128.2,108.5$.

Analysis of 4-chloro-resveratrol (4-Cl-23): ${ }^{1} \mathrm{H}$ NMR $\left(400 \mathrm{MHz}, \mathrm{CD}_{3} \mathrm{OD}\right.$, Supplementary Fig. 58) $\delta 7.33(\mathrm{~d}, J=8.6 \mathrm{~Hz}, 2 \mathrm{H}), 6.93(\mathrm{~d}, J=16.2 \mathrm{~Hz}, 1 \mathrm{H}), 6.75(\mathrm{~d}$, $J=16.2 \mathrm{~Hz}, 1 \mathrm{H}), 6.74(\mathrm{~d}, J=8.6 \mathrm{~Hz}, 2 \mathrm{H}), 6.57(\mathrm{br} \mathrm{s}, 2 \mathrm{H})$.

Analysis of resveratrol (23): ${ }^{1} \mathrm{H}$ NMR $\left(400 \mathrm{MHz}, \mathrm{CD}_{3} \mathrm{OD}\right.$, Supplementary Fig. 59$) \delta 7.33(\mathrm{~d}, J=8.6 \mathrm{~Hz}, 2 \mathrm{H}), 6.93(\mathrm{~d}, J=16.2 \mathrm{~Hz}, 1 \mathrm{H}), 6.77(\mathrm{~d}, J=16.6 \mathrm{~Hz}$, $1 \mathrm{H}), 6.74(\mathrm{~d}, J=8.6 \mathrm{~Hz}, 2 \mathrm{H}), 6.42(\mathrm{~d}, J=2.2 \mathrm{~Hz}, 2 \mathrm{H}), 6.13(\mathrm{t}, J=2.2 \mathrm{~Hz}, 1 \mathrm{H})$.

Crystallization of PItM. PltM crystals were obtained by the hanging drop method with drops containing $0.5 \mu \mathrm{L}$ of PltM $(40 \mathrm{mg} / \mathrm{mL})$ and $0.5 \mu \mathrm{L}$ of the reservoir solution (0.1 M Tris, pH 8, $0.2 \mathrm{M} \mathrm{NaCl}, 0.1 \mathrm{M} \mathrm{CaCl}_{2}$ and $12-17 \%$ PEG 8000). The drops were equilibrated against $0.5 \mathrm{~mL}$ of reservoir solution at $21{ }^{\circ} \mathrm{C}$. Long rodshaped crystals appeared after 1-3 days. The crystals were cryoprotected by a gradual transfer to the solution with the same composition as the reservoir solution, additionally containing $20 \%$ glycerol. The crystals were then frozen by a rapid immersion into liquid nitrogen.

Determination of the crystal structure of PItM. PltM does not contain a sufficient number of Met residues for structure determination by using anomalous signal from selenium atoms in Se-Met PltM. However, PltM contains eight Cys residues, which, if accessible, would react with $\mathrm{Hg}$ salts. $\mathrm{Hg}$ derivative crystals of PltM were prepared by transferring native crystals from its mother liquor to the reservoir solution containing $1 \mathrm{mM}$ ethyl mercury phosphate (EMP) and incubated overnight. These crystals were cryoprotected similarly to the native crystals. X-ray diffraction data for this and other crystals of PltM were collected at $100 \mathrm{~K}$ at the wavelength of $1 \AA$ at synchrotron beamline 22-ID at the Advanced Photon Source at the Argonne National Laboratory (Argonne, IL). All datasets were indexed, integrated and scaled using HKL $2000^{33}$. The structure was determined by the SAD method from the EMP derivative data set (using the wavelength of $1.0 \AA$ ), as follows. A heavy atom search by using direct method-based SHELXD program ${ }^{34}$ initially yielded a substructure of $22 \mathrm{Hg}$ atoms in the asymmetric unit. This $\mathrm{Hg}$ substructure was used as an input in Autosolve in PHENIX suite to obtain initial phases ${ }^{35}$, which were bootstrapped by difference Fourier analysis to yield the total of $33 \mathrm{Hg}$ atoms and a readily interpretable electron density map, with the figure of merit of 0.71 after density modification. The structure of the Hg-derivatized PltM was then iteratively built by using COOT ${ }^{36}$ and refined by using REFMAC $5^{37}$ (Supplementary Table 4). The refined structure contained four monomers of PltM and $33 \mathrm{Hg}$ atoms coordinated to Cys residues per asymmetric unit. A monomer of PltM from this structure was then used as a search model to determine the structure of native PltM by molecular replacement with $\mathrm{Phaser}^{38}$ in CCP4i suite ${ }^{39}$. The native crystal structure of PltM was then iteratively adjusted and refined by using $\mathrm{COOT}^{36}$ and REFMAC5 ${ }^{37}$, respectively. Supplementary Table 4 contains data collection and structure refinement statistics for this and other crystal structures in this study. The crystal structure coordinates and structure factor amplitudes for all crystal structures were deposited in the Protein Data Bank under accession codes specified in Supplementary Tables 4 and 5.

Structure determination for the PItM-FAD intermediate. PltM crystals were soaked in the reservoir solution used to obtained native PltM crystals, with additional $0.5 \mathrm{mM}$ of FAD. The crystals were then gradually transferred to the reservoir solution with $20 \% \mathrm{v} / \mathrm{v}$ PEG 400 and $0.5 \mathrm{mM}$ FAD, prior to quick immersion in 
liquid nitrogen. The diffraction data were collected and processed as described above. Rigid body refinement followed by restrained refinement were performed starting from the structure of apo PltM. FAD was readily discernable in the omit $F_{\mathrm{o}}-F_{\mathrm{c}}$ map. Refinement and model building was carried out as described above.

Structure determination for the holo PItM-FAD complex. Wild-type PltM and the L111Y mutant (each at $40 \mathrm{mg} / \mathrm{mL}$ ) were crystallized by using the reservoir solution composed of $0.1 \mathrm{M}$ Tris, $\mathrm{pH} 8,0.2 \mathrm{M} \mathrm{NaBr}, 0.1 \mathrm{M} \mathrm{CaCl}_{2}$, and 14\% PEG 8000 (10\% PEG 8000 in case of the PltM L111Y mutant). The crystals were gradually transferred to the cryoprotectant solution ( $0.1 \mathrm{M}$ Tris, $\mathrm{pH} 8,0.2 \mathrm{M} \mathrm{NaBr}, 1$ mM FAD, 16\% PEG 8000 (14\% PEG 8000 for the PltM L111Y mutant), 20\% PEG 400 and $1 \mathrm{mM} \mathrm{FAD}$ ) and incubated overnight. Prior to rapid freezing via liquid nitrogen, crystals were briefly transferred to the cryoprotectant solution containing additionally $0.2 \mathrm{M}$ sodium dithionite. The crystal structures were determined by a procedure analogous to that described above.

Structure determination for PItM-FAD-phloroglucinol complex. Native crystals of PltM were transferred to reservoir solution with $0.5 \mathrm{mM} \mathrm{FAD}$ either without or with $1 \mathrm{mM}$ of phloroglucinol for $10 \mathrm{~min}$, then to the cryoprotectant with the same composition, additionally containing $20 \% \mathrm{v} / \mathrm{v}$ PEG 400 . After an overnight incubation, the crystals were rapidly frozen in liquid nitrogen. We tested compounds $\mathbf{1}$, $2,3,8,21,23$, and 24. Data collection, processing, and structure determination were carried out as described above. FAD was clearly discernable in the omit $F_{\mathrm{o}}-F_{\mathrm{c}}$ electron density map. Out of all substrates tested, only compound $\mathbf{1}$ (phloroglucinol) yielded omit $F_{\mathrm{o}}-F_{\mathrm{c}}$ electron density. Phloroglucinol was built into a very strong and featureful polder omit $m F_{\mathrm{o}}-D F_{\mathrm{c}}$ electron density ${ }^{25}$ in three out of four substrate binding sites in the asymmetric unit (Fig. $4 \mathrm{~b}$ in the main text).

\section{Data availability}

The crystal structure coordinates and structure factor amplitudes for all crystal structures were deposited in the Protein Data Bank under accession codes 6BZN, 6BZI, 6BZA, 6BZQ, 6BZT and 6BZZ, as described in Supplementary Tables 4 and 5. NMR spectra, LC-MS, and other chromatographic data are included in the raw format in Supplementary Information. Other data are available from the corresponding authors upon reasonable request.

Received: 21 February 2018 Accepted: 26 February 2019 Published online: 19 March 2019

\section{References}

1. Harris, C. M., Kannan, R., Kopecka, H. \& Harris, T. M. The role of the chlorine substituents in the antibiotic vancomycin: preparation and characterization of mono- and didechlorovancomycin. J. Am. Chem. Soc. 107, 6652-6658 (1985).

2. Gerebtzoff, G., Li-Blatter, X., Fischer, H., Frentzel, A. \& Seelig, A. Halogenation of drugs enhances membrane binding and permeation. ChemBioChem 5, 676-684 (2004).

3. Ruiz-Castillo, P. \& Buchwald, S. L. Applications of palladium-catalyzed C-N cross-coupling reactions. Chem. Rev. 116, 12564-12649 (2016).

4. Tasker, S. Z., Standley, E. A. \& Jamison, T. F. Recent advances in homogeneous nickel catalysis. Nature 509, 299-309 (2014).

5. Kuranaga, T., Sesoko, Y. \& Inoue, M. Cu-mediated enamide formation in the total synthesis of complex peptide natural products. Nat. Prod. Rep. 31, 514-532 (2014).

6. Latham, J., Brandenburger, E., Shepherd, S. A., Menon, B. R. K. \& Micklefield, J. Development of halogenase enzymes for use in synthesis. Chem. Rev. 118, 232-269 (2018).

7. Poor, C. B., Andorfer, M. C. \& Lewis, J. C. Improving the stability and catalyst lifetime of the halogenase RebH by directed evolution. ChemBioChem 15 , 1286-1289 (2014).

8. Payne, J. T., Poor, C. B. \& Lewis, J. C. Directed evolution of RebH for siteselective halogenation of large biologically active molecules. Angew. Chem. 54, 4226-4230 (2015).

9. Frese, M. \& Sewald, N. Enzymatic halogenation of tryptophan on a gram scale. Angew. Chem. 54, 298-301 (2015).

10. Andorfer, M. C. et al. Understanding flavin-dependent halogenase reactivity via substrate activity profiling. ACS Catal. 7, 1897-1904 (2017).

11. Zeng, J. \& Zhan, J. A novel fungal flavin-dependent halogenase for natural product biosynthesis. ChemBioChem 11, 2119-2123 (2010).

12. Zeng, J., Lytle, A. K., Gage, D., Johnson, S. J. \& Zhan, J. Specific chlorination of isoquinolines by a fungal flavin-dependent halogenase. Bioorg. Med. Chem. Lett. 23, 1001-1003 (2013).

13. Agarwal, V. et al. Biosynthesis of polybrominated aromatic organic compounds by marine bacteria. Nat. Chem. Biol. 10, 640-647 (2014).
14. Yeh, E., Blasiak, L. C., Koglin, A., Drennan, C. L. \& Walsh, C. T. Chlorination by a long-lived intermediate in the mechanism of flavin-dependent halogenases. Biochemistry 46, 1284-1292 (2007).

15. Zhu, X. et al. Structural insights into regioselectivity in the enzymatic chlorination of tryptophan. J. Mol. Biol. 391, 74-85 (2009).

16. Dong, C. et al. Tryptophan 7-halogenase (PrnA) structure suggests a mechanism for regioselective chlorination. Science 309, 2216-2219 (2005).

17. Flecks, $\mathrm{S}$. et al. New insights into the mechanism of enzymatic chlorination of tryptophan. Angew. Chem. 47, 9533-9536 (2008).

18. Podzelinska, K. et al. Chloramphenicol biosynthesis: the structure of CmlS, a flavin-dependent halogenase showing a covalent flavin-aspartate bond. J. Mol. Biol. 397, 316-331 (2010).

19. Menon, B. R. et al. Structure and biocatalytic scope of thermophilic flavindependent halogenase and flavin reductase enzymes. Org. Biomol. Chem. 14, 9354-9361 (2016).

20. Bitto, E. et al. The structure of flavin-dependent tryptophan 7-halogenase RebH. Proteins 70, 289-293 (2008).

21. Nowak-Thompson, B., Chaney, N., Wing, J. S., Gould, S. J. \& Loper, J. E. Characterization of the pyoluteorin biosynthetic gene cluster of Pseudomonas fluorescens Pf-5. J. Bacteriol. 181, 2166-2174 (1999).

22. Yan, Q., Philmus, B., Chang, J. H. \& Loper, J. E. Novel mechanism of metabolic co-regulation coordinates the biosynthesis of secondary metabolites in Pseudomonas protegens. eLife 6, e22835 (2017).

23. Dorrestein, P. C., Yeh, E., Garneau-Tsodikova, S., Kelleher, N. L. \& Walsh, C. T. Dichlorination of a pyrrolyl-S-carrier protein by FADH2 dependent halogenase PltA during pyoluteorin biosynthesis. Proc. Natl Acad. Sci. USA 102, 13843-13848 (2005).

24. Pang, A. H., Garneau-Tsodikova, S. \& Tsodikov, O. V. Crystal structure of halogenase PltA from the pyoluteorin biosynthetic pathway. J. Struct. Biol. 192, 349-357 (2015).

25. Liebschner, D. et al. Polder maps: improving OMIT maps by excluding bulk solvent. Acta Crystallogr. D73, 148-157 (2017).

26. Yeh, E. et al. Flavin redox chemistry precedes substrate chlorination during the reaction of the flavin-dependent halogenase RebH. Biochemistry 45, 7904-7912 (2006)

27. Ortiz-Maldonado, M., Ballou, D. P. \& Massey, V. A rate-limiting conformational change of the flavin in $p$-hydroxybenzoate hydroxylase is necessary for ligand exchange and catalysis: studies with 8-mercapto- and 8-hydroxy-flavins. Biochemistry 40, 1091-1101 (2001).

28. Payne, J. T., Andorfer, M. C. \& Lewis, J. C. Regioselective arene halogenation using the FAD-dependent halogenase RebH. Angew. Chem. 52, 5271-5274 (2013).

29. Kuzmic, P. Program DYNAFIT for the analysis of enzyme kinetic data: application to HIV proteinase. Anal. Biochem. 237, 260-273 (1996).

30. Tan, H. et al. Structure-activity relationships and optimization of acyclic acylphloroglucinol analogues as novel antimicrobial agents. Eur. J. Med. Chem. 125, 492-499 (2017)

31. Ho, S. N., Hunt, H. D., Horton, R. M., Pullen, J. K. \& Pease, L. R. Site-directed mutagenesis by overlap extension using the polymerase chain reaction. Gene 77, 51-59 (1989).

32. Pongtharangkul, T. et al. Kinetic properties and stability of glucose dehydrogenase from Bacillus amyloliquefaciens SB5 and its potential for cofactor regeneration. AMB Express 5, 68 (2015).

33. Otwinowski, Z. \& Minor, W. Processing of X-ray diffraction data collected in oscillation mode. Methods Enzymol. 276, 307-326 (1997).

34. Sheldrick, G. M. Experimental phasing with SHELXC/D/E: combining chain tracing with density modification. Acta Crystallogr. D 66, 479-485 (2010).

35. Adams, P. D. et al. PHENIX: a comprehensive Python-based system for macromolecular structure solution. Acta Crystallogr. D 66, 213-221 (2010).

36. Emsley, P. \& Cowtan, K. Coot: model-building tools for molecular graphics. Acta Crystallogr. D 60, 2126-2132 (2004)

37. Murshudov, G. N. et al. REFMAC5 for the refinement of macromolecular crystal structures. Acta Crystallogr. D 67, 355-367 (2011).

38. McCoy, A. J. et al. Phaser crystallographic software. J. Appl. Crystallogr. 40, 658-674 (2007).

39. Winn, M. D. et al. Overview of the CCP4 suite and current developments. Acta Crystallogr. D 67, 235-242 (2011).

\section{Acknowledgements}

This work was supported by a NSF CAREER Award MCB-1149427 (to S.G.-T.), a grant as part of the National Center for Advancing Translational Sciences (UL1TR000117) (to S.G.-T. and O.V.T.), and by startup funds from the College of Pharmacy at the University of Kentucky (to S.G.-T. and O.V.T.). S.M. is a recipient of a 2018 long-term visit fellowship from the Yamada Science Foundation, Japan. The authors thank Dr. James J. La Clair and Prof. Michael D. Burkart from UCSD for valuable discussion and suggestions on optimization of PltM reaction conditions for halogenation. The authors are grateful to the staff of sector SER-CAT of Advanced Photon Source of the Argonne National Laboratory for support during the remote data collection. 


\section{Author contributions}

A.H.P. and S.M. performed mutagenesis studies. A.H.P. performed crystallization and structure determination of PltM. S.M. performed halogenation assays, kinetic studies, reaction optimization, enzyme immobilization, product purification, and analyzed HPLC and LC-MS data. N.T.C. performed chemical synthesis and NMR analyses. S.M., A.H.P., S.G.-T. and O.V.T. designed the study, discussed the results, and wrote the manuscript.

\section{Additional information}

Supplementary Information accompanies this paper at https://doi.org/10.1038/s41467019-09215-9.

Competing interests: The authors declare no competing interests.

Reprints and permission information is available online at http://npg.nature.com/ reprintsandpermissions/

Journal peer review information: Nature Communications thanks the anonymous reviewers for their contribution to the peer review of this work.
Publisher's note: Springer Nature remains neutral with regard to jurisdictional claims in published maps and institutional affiliations.

(c) (i) Open Access This article is licensed under a Creative Commons Attribution 4.0 International License, which permits use, sharing, adaptation, distribution and reproduction in any medium or format, as long as you give appropriate credit to the original author(s) and the source, provide a link to the Creative Commons license, and indicate if changes were made. The images or other third party material in this article are included in the article's Creative Commons license, unless indicated otherwise in a credit line to the material. If material is not included in the article's Creative Commons license and your intended use is not permitted by statutory regulation or exceeds the permitted use, you will need to obtain permission directly from the copyright holder. To view a copy of this license, visit http://creativecommons.org/ licenses/by/4.0/.

(C) The Author(s) 2019 